\title{
THE METABOLIC RESPONSES OF THE COMMON IGUANA, IGUANA IGUANA, TO WALKING AND DIVING*
}

\author{
WALTER R. MOBERLY† \\ Department of Zoology, University of Michigan, Ann Arbor, Michigan
}

(Received 20 February 1968)

\begin{abstract}
Strictly aerobic metabolism in Iguana iguana during walking was highly temperature-dependent, as was the maximum rate of walking without the incurrence of an oxygen debt. The absolute maximum rate of walking aerobically correlated with the temperature of the maximum metabolic scope.

2. The energetic cost of walking did not increase with temperature, but rose curvilinearly with speed, the efficiency being greatest at the higher rates of walking.

3. Diving iguanas could remain submerged for up to $4 \frac{1}{2} \mathrm{hr}$, tolerating blood lactate levels as high as $320 \mathrm{mg}$ per cent.

4. Blood $\mathrm{pH}$ dropped as low as 6.9 during a dive.
\end{abstract}

\section{INTRODUCTION}

THIs paper will deal with the study of metabolism and its side-effects in iguanas actually engaged in types of activity to be expected in nature. The two activities considered are diving and walking. Both had to be studied under artificial conditions because of the nature of the parameters being measured, but it is believed that the data obtained are relevant to natural situations.

Walking at a measured rate is of particular interest because it is an activity regularly undertaken in the field by iguanas. It is also convenient to study as the duration and severity of the exercise are easy to regulate. According to Fry's (1947) hypothesis, discussed in the previous paper (Moberly, 1968), the temperature where the metabolic scope is greatest should correspond with the temperature where that animal can sustain the highest rate of movement for the longest length of time. In the iguana this should occur at about $32^{\circ} \mathrm{C}$ (Moberly, 1968). Other parameters of interest can also be observed in walking experiments. These involve the relative efficiencies of muscular exercise at varying speeds and temperatures. For instance, man's efficiency in running increases up to a point as the rate increases, after which it begins to decrease (Karpovich, 1965). In sock-eye salmon (Oncorhynchus nerka), the efficiency of swimming shows much the same sort of phenomenon. An additional consideration is applicable to poikilotherms. In sock-eye salmon, the cost of

* Work supported by an NSF Predoctoral Fellowship for 1962-63 and NIH Predoctoral Fellowships for 1963-66.

This paper is part of a dissertation submitted in partial fulfillment of the requirements for the Ph.D. degree at the University of Michigan.

† Present address: Department of Biology, University of Oregon, Eugene, Oregon. 
their moving at a certain rate increases exponentially as the body temperature rises (Brett, 1963).

Iguanas in nature will usually attempt to escape into the nearest body of water by diving beneath the surface and remaining submerged until the danger to them is no longer present (Moberly, 1968). The duration of the dive will be influenced by many factors. These include the capacity for anaerobic metabolism, extent of activity beneath the surface, ability to mobilize energy reserves, temperature, physiological adjustments such as bradycardia, and tolerance of large shifts in several aspects of the animal's body chemistry. Since diving was the most common method of escape from danger for the iguana in wide areas of Colombia, it would appear of vital importance to the lizard that the ability to tolerate submergence be developed to a high degree.

\section{MATERIALS AND METHODS}

Nine iguanas ranging in size from 570 to $1220 \mathrm{~g}$ were used in the study of metabolism during walking. Animals were tested at varying speeds on the treadmill shown in Fig. 1.

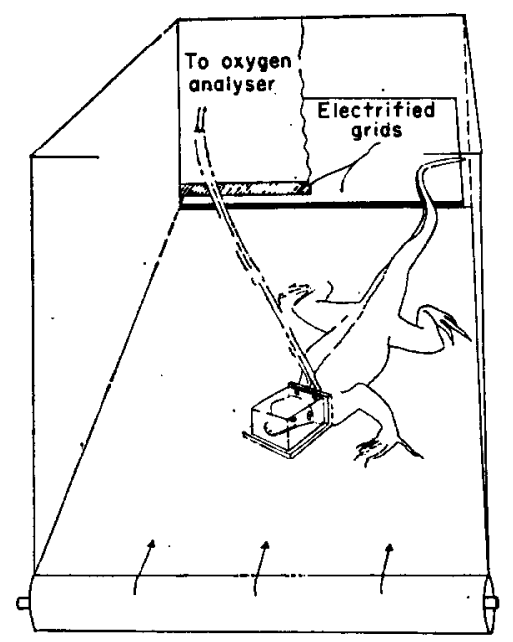

FIG. 1. The treadmill used in all studies of metabolism at various rates of running. Note the electrified metal plate and table at the back of the treadmill. These were used to deliver shocks to the tail of the iguana if it stopped walking.

This was located in a walk-in constant-temperature cabinet that could be maintained within $1^{\circ} \mathrm{C}$ of the desired level. Running was maintained by the electrically charged table at the back of the treadmill. When the lizard stopped exercising and allowed itself to ride back on the treadmill, it received a light shock on the tail from this device. The iguanas appeared to learn to maintain position very quickly and usually were walking regularly by the end of the first trial. After two training trials; a test was made in which oxygen consumption was monitored continuously with a paramagnetic oxygen analyzer as described previously (Moberly, 1968). In this case a modified mask of neoprene and Plexiglass was used, so that the animal's vision was unimpaired (Fig. 1). The lizards were placed on the treadmill and first allowed a minimum of $4 \mathrm{hr}$ to come to thermal equilibrium and resting levels of oxygen 
consumption. They were then tested for a total of $1 \mathrm{hr}$ or until they refused to walk and were threatened with injury by the treadmill. At this point they were considered exhausted and the test was terminated. At the termination of a test, a heart puncture was made with a hypodermic syringe and a No. 26 needle and the blood analyzed for lactic acid as described in the previous paper (Moberly, 1968). Body temperature was also taken at this time.

The diving experiments were undertaken in Columbia in a swimming pool. The pool had recently been converted into a fish pond and had a large algal bloom which made the water as murky as that of the muddy rivers in the area. It varied in depth from 3 to $8 \mathrm{ft}$. Forty-one adult iguanas were used, most within 1 day of capture and all within 3 days. Resting animals were quickly removed from the heavy cloth bags in which they were kept, a string was looped around their waists, and they were either tossed or chased the 4-5 ft into the swimming pool. Body temperatures at this time ranged from 22 to $27^{\circ} \mathrm{C}$. Almost all of the lizards submerged immediately, and only those that did were used. Movement under the water could be observed by watching the string tied to the animals, and this also allowed retrieval after specified intervals of time. Some of the iguanas were allowed to remain submerged to the limit of their voluntary tolerance. At the end of the dive the animals were quickly recovered and a heart puncture was made as described above. Body temperature was then measured. The blood collected was divided into two parts; one was deproteinized in perchloric acid, and the other was kept refrigerated in a lightly heparinized syringe under anaerobic conditions. These samples were later analyzed for lactic acid and blood glucose as described previously (Moberly, 1968), and for $\mathrm{pH}$ using a Radiometer micro-blood pH electrode.

\section{RESULTS AND DISCUSSION}

\section{Walking on the treadmill}

General considerations. The oxygen consumption of an iguana during an hour's run on the treadmill was generally as shown in Fig. 2. Oxygen consumption rose

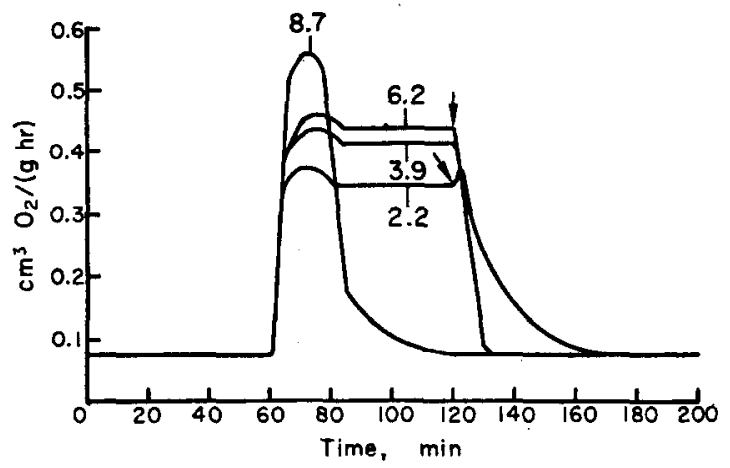

FIG. 2. Typical form of the results obtained when Iguana iguana was run on the treadmill at different speeds at the same body temperature. All runs were started at $60 \mathrm{~min}$ and terminated at the point indicated by the arrows. The numbers refer to the rate of walking in $\mathrm{m} / \mathrm{min}$.

rapidly with the beginning of activity, overshooting the level at which it finally stabilized. This level is referred to as $M_{v}$ in the ensuing discussion. A small increase in oxygen consumption usually occurred when the test was terminated, and this was usually followed by a rapid fall to a resting level $\left(M_{r}\right)$. This resting 
level was generally regained in less than $10 \mathrm{~min}$, but a period of up to $30 \mathrm{~min}$ was required by some animals. The energetic cost of walking on the treadmill was taken as the difference between $M_{w}$ and $M_{r}$. Discussions of energetic cost in this paper always refer to this net value. The size range of the lizards tested was relatively small, so differences due to variation in the distance traversed per step were minimal. This obviated the need for expressing the results in terms of the body lengths moved per unit time as has been done with fish of varying size (Bainbridge, 1958).

The effect of temperature on the cost of activity. Iguanas were tested at three different treadmill speeds and a variety of temperatures to ascertain the thermal dependence of the metabolic cost of activity. A summary of data for all of the lizards studied in this manner is presented in Fig. 3. In the iguana increasing body

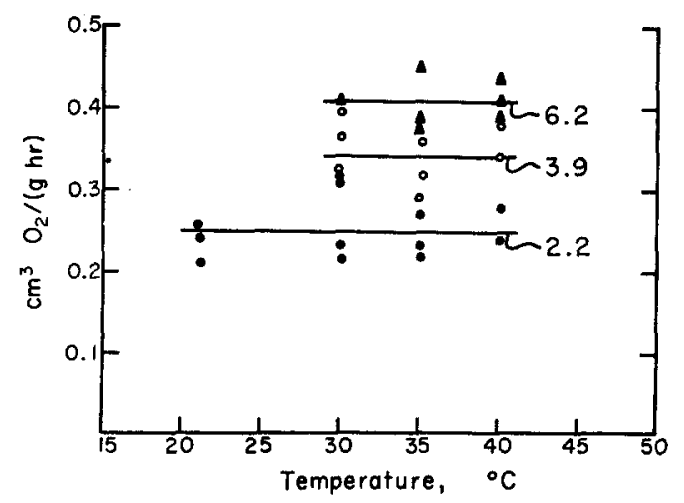

FIG. 3. The oxygen consumed at different rates of walking at various temperatures. The numbers refer to the speed of walking in $\mathrm{m} / \mathrm{min}$, and the lines are drawn along the means of the points at a given speed for all temperatures. $=$ the oxygen consumed while walking at $2.2 \mathrm{~m} / \mathrm{min}, O$ at $3.9 \mathrm{~m} / \mathrm{min}$, and $\Delta$ at $6.2 \mathrm{~m} / \mathrm{min}$.

temperature has little or no effect on the metabolic cost of activity at a given rate. Brett (1963) found that the metabolic cost of swimming at a particular speed increased with a $Q_{10}$ of $1.1-1.2$ in young sock-eye salmon, but that this effect was dampened at the higher speeds. This rise in energetic cost is surprising because the viscosity of water declines with increasing temperature, and less energy should be required to move through it. The energetic cost of activity in the iguana might also have a weak temperature-dependence, but a $Q_{10}$ of $1 \cdot 1-1 \cdot 2$ could easily be masked by the extent of the variation in the relatively few data. However, it should be noted that Brett's experimental design differs importantly from that used in this study. His fish were acclimated before each run to the temperature to be used, whereas the iguanas were not. While it is doubtful that lizards acclimate to temperature to as great an extent as fish, this is nonetheless a possible source of difference.

The effect of walking speed on the cost of activity. With the knowledge that the cost of walking at a given speed is independent of temperature, it was possible to 
combine all of the data obtained for walking at various speeds and temperatures and calculate the metabolic cost of movement at the different speeds. The results are shown in Fig. 4. The rate of increase in cost per unit increase in speed decreases as the speed increases, indicating that the process of running is becoming more efficient at higher speeds. This is indicated in Table 1 by the fact that the cost to

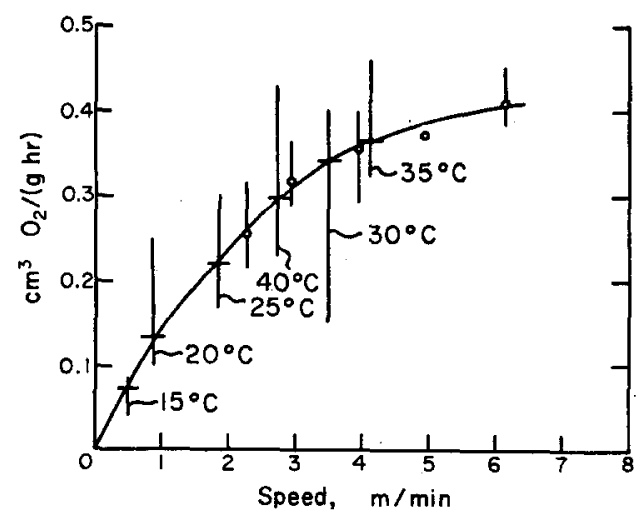

FIG. 4 The oxygen consumed by an iguana walking at various speeds on the treadmill. The vertical lines with temperatures attached represent the range of metabolic scope at the designated temperature. These are positioned along the abcissa so that the means (horizontal lines) fall along the curve. The other figures are the means $(O)$ and ranges $(\mid)$ of oxygen consumption required for activity by iguanas walking on the treadmill at various speeds. The curve is fitted to these data by eye.

TABLE 1-ThE METABOLIC $\operatorname{cost}\left(\mathrm{ml} \mathrm{O}_{2} \mathrm{~g}^{-1} \mathrm{hr}^{-1}\right)$ FOR AN IGUANA WEIGHING FROM 520 TO $1220 \mathrm{~g}$ TO WALK $1 \mathrm{~km}$ AT VARIOUS SPEEDS

\begin{tabular}{cc}
\hline $\begin{array}{c}\text { Speed } \\
(\mathrm{m} / \text { min })\end{array}$ & $\mathrm{ml} \mathrm{O}_{\mathbf{z}} /(\mathrm{g} \mathrm{hr})$ \\
\hline 2.2 & 1.9 \\
1.8 & 1.9 \\
3.9 & 1.5 \\
4.8 & 1.3 \\
6.2 & 1.0 \\
\hline
\end{tabular}

run $1 \mathrm{~km}$ at the different speeds used for the hour-long activity period steadily declines as the speed increases past $2.8 \mathrm{~m} / \mathrm{min}$. The cost at $6.2 \mathrm{~m} / \mathrm{min}$ is only 57 per cent of the cost at $2.8 \mathrm{~m} / \mathrm{min}$. The shape of the curve in Fig. 4 is like that seen by Brody (1945) for the rates of walking of horses. If the speed of walking by the iguana increased sufficiently, the energetic efficiency would probably begin to drop, but this point occurs past the maximum speed sustainable with aerobic metabolism alone. 
The effect of temperature on the capacity for activity. It is now possible to consider the question of what activity at a body temperature near that of the maximum metabolic scope gains for an iguana. In the case of strictly aerobic activity, the advantage gained is an increase in the maximum sustainable rate. Table 2 shows the bounds within which the maximum sustainable rate of walking falls, the duration of walking at the upper bound before becoming exhausted, and the blood lactate concentrations after walking at the upper and lower bounds. The treadmill speeds used could be varied by $0.6-0.8 \mathrm{~m} / \mathrm{min}$ increments. The bounds mentioned above were determined by measuring the maximum treadmill speed that could be maintained by the iguana for $1 \mathrm{hr}$, and then finding a slightly higher speed that the animal could only maintain for 10-21 min. It should be noted in Table 2 that blood lactate levels are elevated above resting levels of $4 \mathrm{mg}$ per cent (Moberly, 1968) even at walking speeds sustainable for the entire hour. However, as Brett (1963) points out, it is probably not possible to undertake any amount of activity without the establishment of a small amount of oxygen debt, representing the tolerable lag between oxygen supply and demand. The critical factor is that this debt remains at a relatively low level during activity, indicating that metabolism is predominantly aerobic. At the speed just above the maximum treadmill speed that can be maintained for $1 \mathrm{hr}$, blood lactate levels are much higher. They are, in fact, as great as those seen in restrained animals struggling to exhaustion (Moberly, 1968). If Fry's (1947) hypothesis concerning metabolic scope is correct (see Moberly, 1968, for a discussion of this hypothesis), then the maximum speed that an iguana can sustain by predominantly aerobic means should be determined by the metabolic scope at the temperature at which it is walking. In Fig. 4 data on metabolic scope (from Moberly, 1968) have been plotted so that the means fall along the curve of cost of activity. This should allow determination of the highest walking speed that could be sustained aerobically at a particular temperature. The results of this determination are in good agreement with the observed maximum sustained speeds shown in Table 2. The performance of the iguana is therefore consistent with Fry's hypothesis; the temperature at which the maximum metabolic scope occurs is also that at which the highest level of aerobic activity is sustained.

\section{Diving}

Duration. Iguanas voluntarily remained submerged 50-270 min (median, 65 min; mean, $82 \mathrm{~min}$ ). These are remarkably long periods to remain submerged for an animal that normally breathes air and lives in trees. The body temperature of iguanas at the end of dives always fell to a value between $25^{\circ}$ and $26^{\circ} \mathrm{C}$, the temperature range of rivers in the immediate vicinity of Cali, Colombia, at the time of the investigation.

Upon diving the lizards would quickly disappear. They sank to the bottom and remained there quietly in some cases, but in others there was a great deal of under-water movement. At about $30 \mathrm{~min}$, they would usually come up from the bottom to a depth from which they could view the surroundings. They surfaced if all appeared clear. If it did not, they again sank out of sight without taking any air 


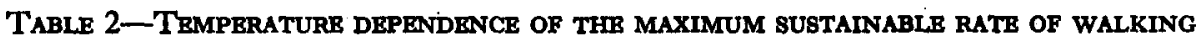

\begin{tabular}{cccccc}
\hline & $\begin{array}{c}\text { Bounds within which the } \\
T_{b}\end{array}$ & $\begin{array}{c}\text { maximum sustainable rate }(R) \\
\text { of walking falls (m/min) }\end{array}$ & $\begin{array}{c}\text { Duration of walking } \\
\text { sustainable at upper } \\
\text { bound (min) }\end{array}$ & \multicolumn{2}{c}{ Lactate conc. (mg \%) } \\
\cline { 5 - 6 }$\left({ }^{\circ} \mathrm{C}\right)$ & bower & Lound & $\begin{array}{c}\text { Upper } \\
\text { bound }\end{array}$ \\
\hline 20 & $2 \cdot 2 \leqslant R<2 \cdot 8$ & 21 & 34 & 121 \\
25 & $2 \cdot 8 \leqslant R<3.8$ & 14 & 28 & 110 \\
30 & $6 \cdot 2 \leqslant R<7.5$ & 10 & 41 & 133 \\
35 & $6 \cdot 2 \leqslant R<8.7$ & 17 & 29 & 148 \\
40 & $6 \cdot 2 \leqslant R<7.5$ & 12 & 48 & 139 \\
\hline
\end{tabular}

at the surface. Usually the animal would inspect the situation again at about $45 \mathrm{~min}$. This was the last inspection before breaking water, and no amount of threatening could get them to submerge again. The lizards were then considered to be exhausted.

Blood lactate during a dive. The results of the analyses for blood lactate concentration are shown in Fig. 5. This concentration is plotted as a function of the duration of the dive. Two groups of animals are apparent and are roughly separated

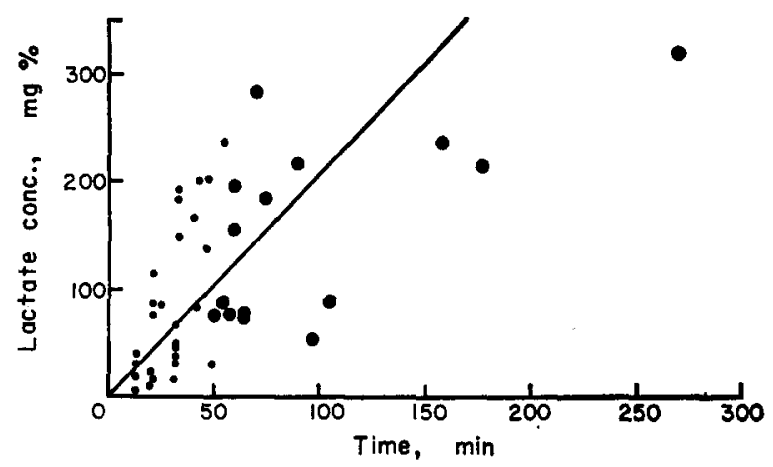

FIG. 5. Blood lactate concentrations as a function of dive duration. The points enclosed within circles represent values for animals that remained submerged as long as they would voluntarily tolerate. The line represents calculated values derived as described in the text.

by the solid line. The group represented by the data below the line is comprised of lizards that sank to the bottom and remained inactive. These animals could remain submerged for up to $4 \frac{1}{2} \mathrm{hr}$ with oxygen debts not in excess of those seen for the other group at $1 \mathrm{hr}$. This second group, represented by the data above the line, is comprised of lizards that engaged in various amounts of swimming under water. This activity could have been highly disadvantageous for two reasons. It naturally would increase energy demands and thus cause a more rapid build-up of lactic acid. The second reason would be the possible disruption of normal diving circulatory 
responses. In all reptiles investigated to date, including the iguana, bradycardia is associated with diving (Belkin, 1963, 1964). In water snakes, there is also a restriction of blood flow to the muscles, and thus a restriction of central lactate build-up (Murdaugh \& Jackson, 1962). Under-water activity may necessitate more circulation to the anoxic muscles, with an increase in lactate seen at the heart.

The points in Fig. 5 surrounded by an outer circle represent those iguanas which stayed under the water until "exhausted". It is of interest that the blood lactate levels of many of these animals were relatively low: some are only a third of the values attained by animals that remained voluntarily submerged for much longer periods. It would appear that the reason for the termination of the dive must be sought in some other factor than the build-up in the blood of intolerable levels of lactic acid. One possibility is the depletion of carbohydrate reserve available for utilization in anaerobic metabolism by conversion to lactate.

Some iguanas successfully tolerated concentrations of blood lactate up to $320 \mathrm{mg}$ per cent during dives (Fig. 5). This is curious, for animals running on the treadmill all stopped activity at about $140 \mathrm{mg}$ per cent, while those restrained on the jig never reached more than $160 \mathrm{mg}$ per cent during bursts of activity. Evidently the upper limit of lactate tolerance in this lizard is considerably higher than the concentration at which muscular activity is no longer voluntarily undertaken. This concentration, about $150 \mathrm{mg}$ per cent, corresponds very closely with the level at which man and dogs become exhausted and no longer capable, or willing, to undertake further exercise (Karpovich, 1965). Since blood lactate levels in excess of $150 \mathrm{mg}$ per cent were found in diving lizards, it is of interest to ask if this inhibited under-water swimming activities. Those individuals in Fig. 5 which fell above the solid line and which had blood lactate concentrations in excess of $150 \mathrm{mg}$ per cent carried on vigorous under-water swimming before but never after $25 \mathrm{~min}$ of submergence. Blood lactate values never exceeded $110 \mathrm{mg}$ per cent within the first $25 \mathrm{~min}$ of submergence, but were in excess of $150 \mathrm{mg}$ per cent in many individuals after $30-40 \mathrm{~min}$. Thus it would appear that at about $25-30 \mathrm{~min}$ blood lactate concentrations closely approached or exceeded the level of $150 \mathrm{mg}$ per cent in active individuals, and since swimming was not seen after this time the hypothesis that it is also inhibited by these levels of lactate is supported. This could be easily tested by injecting lactate into an animal before a dive or run.

The heavy line in Fig. 5 represents values for blood lactate concentration that should be seen in an iguana if it were depending entirely on anaerobic metabolism in maintaining its bodily functions at the same rate as an animal resting in the air at $25^{\circ} \mathrm{C}$. The same assumptions are made as in the calculations in the previous paper (Moberly, 1968) for the equivalent amounts of high-energy compounds derived from anaerobic and aerobic metabolism. The only different assumption made here is that the lactate concentrations in the blood are equal to those in all other tissues of the body. This is probably a close estimate in the absence of muscular activity and restriction of blood flow to the periphery. However, it must be low if there is activity or differential blood flow. Lizards that were inactive below the surface of the water must have had far lower rates of metabolism than calculated as being 
necessary for maintenance in air. At $270 \mathrm{~min}$ one animal had metabolized at only about 60 per cent of the calculated rate. Belkin (1963) has reported on the very striking bradycardia in the iguana during a dive. When the animal first enters the water, its heart rate falls to only one beat every $5 \mathrm{~min}$, and then it slowly increases over the duration of the dive. This bradycardia is even more pronounced than that seen in other diving animals. Bradycardia is associated with drastic reduction of the peripheral blood flow in resting diving seals, ducks and penguins. In these animals the oxygen debt is also less than calculated. Scholander (1940) postulated that when the flow of blood to the periphery was reduced in these animals, the lack of oxygen somehow triggered a slowing of the metabolism in these tissues.

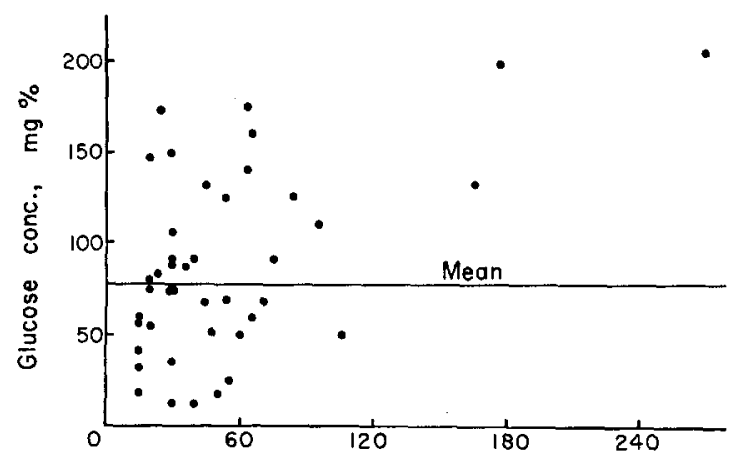

Fic. 6. Blood glucose levels as a function of the duration of dives in the iguana. The line marked mean is the mean value for freshly caught animals previous to a dive.

Blood glucose during a dive. No significant trend appears to exist in blood glucose concentration with respect to the duration of dives (Fig. 6). Some concentrations for very long dives are elevated, but otherwise there are as many values below the mean for non-diving animals as there are above it. The blood glucose levels of diving iguanas also do not correlate with blood lactate levels. It therefore appears that in diving, as in violent struggling (Moberly, 1968), blood glucose and more remote stores of carbohydrate play little role in the capacity for activity. A possible explanation for the high values associated with long dives may be found in increased epinephrine levels during the dive. Epinephrine can bring about large increases in blood glucose levels. Increased secretion of this hormone has been correlated in the dog with decreases in the oxygen content and $\mathrm{pH}$ of arterial blood (Ludeman et al., 1955; Nahas, 1959). Oxygen depletion of the blood and lowered $\mathrm{pH}$ are features of dives by iguanas, with the magnitude of the changes increasing with the duration of the dive.

Blood $p H$ during a dive. The blood $\mathrm{pH}$ 's of iguanas dropped drastically during diving (Fig. 7). There appear to be two groups of animals in this case as in the data on lactic acid accumulation shown in Fig. 5. One group reached $\mathrm{pH} 6.9$ within 30-50 min, whereas the other group did not do so for as much as $4 \frac{1}{2} \mathrm{hr}$. As was 
found for the data on lactate concentration during a dive, no clear-cut line exists between those animals that emerged and those that were still submerged. This suggests that the lowering of blood $\mathrm{pH}$ to a particular level is not the factor responsible for the termination of a dive.

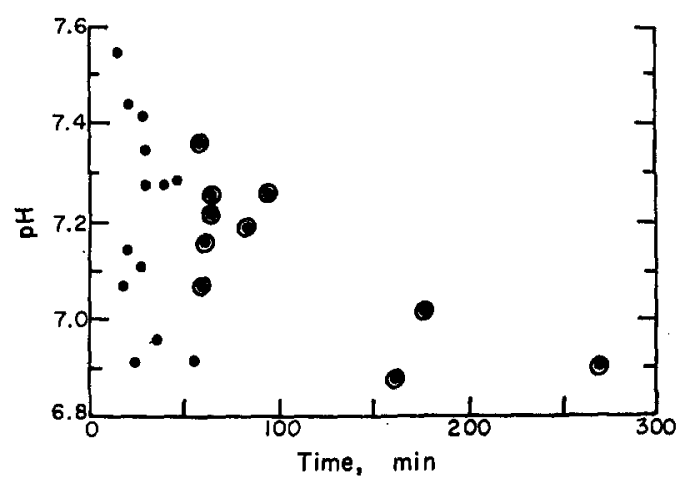

Fic. 7. Blood pH as a function of the duration of dives in the iguana. The points enclosed within circles represent values for animals that remained submerged as long as they would voluntarily tolerate.

The similarity of the patterns by which hydrogen ion and lactic acid concentrations increase in the blood of the iguanas as the dive progresses suggested that the former was a function of the latter. A linear relation is apparent between blood $\mathrm{pH}$ and lactate concentration (Fig. 8). This is expected, as the titration curve of iguana blood in the range $\mathrm{pH} 6.5-8.5$ is essentially a straight line with $\mathrm{HCl}$.

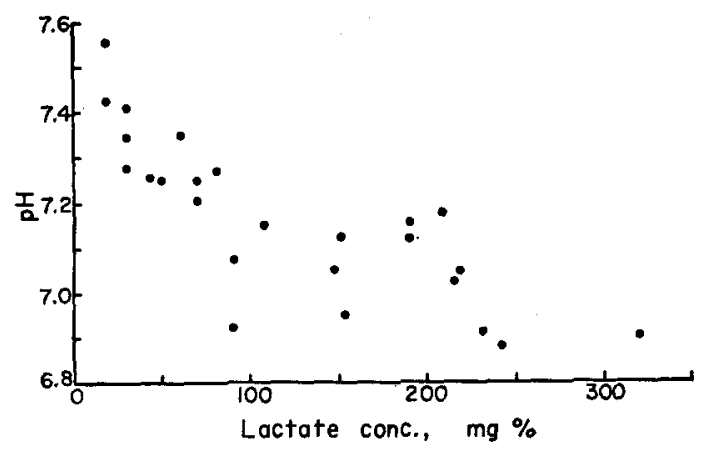

Fig. 8. Blood pH as a function of blood lactate concentration in the iguana.

The large amounts of lactic acid present in the blood for a relatively small shift in $\mathrm{pH}$ raised the question as to whether or not iguana blood had some special buffering power. If the blood was assumed to have a $p \mathrm{CO}_{2}$ of $40 \mathrm{~mm} \mathrm{Hg}$ at the beginning of the dive, and that this was maintained at this or slightly increasing levels as seen in diving turtles (Robin et al., 1964), then no special mechanisms had 
to be invoked to account for the buffering capacity. The only requirements for buffering during a long dive are a low metabolic rate and maintenance of $\mathrm{CO}_{2}$ levels.

\section{SUMMARY AND CONCLUSIONS}

As was pointed out in the previous paper (Moberly, 1968), in iguanas aerobic metabolism seems to play a relatively minor role in vigorous bursts of restrained activity. This is also reflected in measurements made on walking animals.

The capacity of iguanas for aerobic activity is not great, and it is highly temperature-dependent. At $20^{\circ} \mathrm{C}, 2.2 \mathrm{~m} / \mathrm{min}$ is the highest rate of walking that the lizards can sustain by aerobic metabolism alone, whereas at $30^{\circ} \mathrm{C}$, it is $6 \cdot 2 \mathrm{~m} / \mathrm{min}$. The energetic cost of walking does not increase with temperature, but rises curvilinearly with speed, the efficiency being greatest at the higher rates of progression. The speed at which an iguana can walk without incurring an oxygen debt correlates well with the metabolic scopes available at the various temperatures. As such, the optimal temperature for aerobic activity would be at about $32^{\circ} \mathrm{C}$. While the amount of aerobic activity is small, it is nonetheless important, for contraction of any sort of an oxygen debt while exposed during feeding or courtship would seriously impair the capacity of the lizards to escape from a predator.

Another question brought up in the previous paper (Moberly, 1968) was whether or not iguanas could use their considerable capacity for anaerobic metabolism for some other adaptive purpose. This was clearly seen to be the case with respect to diving. It is a valuable escape mechanism for an animal that lives near water and has a low metabolic rate. By diving, iguanas can with relatively few specializations avoid predators for up to $4 \frac{1}{2} \mathrm{hr}$ in almost total safety. The blood lactate concentrations tolerated during a dive are very high $(320 \mathrm{mg}$ per cent). This amount of lactic acid is easily buffered so that $\mathrm{pH}$ dropped only 0.6 unit, because the $\mathrm{CO}_{2}$ tension in the blood is not allowed to drop due to the cessation of breathing. The above capabilities are not spectacular in the light of the abilities of some diving reptiles, namely turtles, which can remain submerged up to $120 \mathrm{hr}$ and tolerate blood lactate concentrations of up to $585 \mathrm{mg}$ per cent (Robin et al., 1964). They are remarkable, however, when one considers that diving by an iguana is a rarely used mechanism in an arboreal animal.

Acknowledgements-The author wishes to thank Dr. William Dawson for critical help during all stages of the work. Much aid was also rendered by Dr. Donald Tinkle, Billie Frye, David Shappirio and Claude Hibbard. Successful completion of the field work in Colombia would not have been possible without the co-operation of Drs. Carlos Lehmann, Federico Medem, Luis and Ignacio Borrero. Señores Marco Galarza and Carlos Velasquez provided invaluable field assistance.

\section{REFERENCES}

BaINBridgr R. (1958) The speed of swimming of fish as related to size and to the frequency and amplitude of the tail beat. F. exp. Biol. 35, 108-133.

BeLkin D. A. (1963) Diving bradycardia in the iguana. Physiologist 6, 137 (abstract). 
Belkin D. A. (1964) Variations in heart rate during voluntary diving in the turtle Pseudemys concinna. Copeia 2, 321-330.

BRETT J. R. (1963) The energy required for swimming in young sockeye salmon with a comparison of the drag force on a dead fish. Trans. R. Soc. Can. (series 4) 1, 441-457.

Brody S. (1945) Bioenergetics and Growth. Reinhold, New York.

Fry F. E. J. (1947) Effects of the Environment on Animal Activity. Publs. Ontario Fish. Res. Lab. No. 68.

Karpovich P. V. (1965) Physiology of Muscular Activity (6th edn). Saunders, Philadelphia.

Ludeman H. H., Filbert M. G. \& Cornblath M. (1955) Application of a fluorometric method for adrenaline-like substances in peripheral plasma. 9. appl. Physiol. 8, 59-66.

MOBERLY W. R. (1968) The metabolic responses of the common iguana, Iguana iguana, to activity under restraint. Comp. Biochem. Physiol. 27, 1-20.

MuRDAugh H. V. \& JACKSON S. E. (1962) Heart rate and blood lactic acid concentration during experimental diving of water snakes. Am.F. Physiol. 202, 1163-1165.

NaHas G. G. (1959) Influence du tamponnement du gaz carbonique sur les catecholomines du sang au cours de l'hypercapnie. C. r. hebd. Seanc. Acad. Sci., Paris. 248, 294-297.

Robin E. D., Vegter J. W., Murdaugh H. V. \& Mrlien J. E. (1964) Prolonged anaerobiosis in a vertebrate: anaerobic metabolism in the freshwater turtle. $\%$. cell. comp. Physiol. 63, 287-297.

SCHOLANDER P. F. (1940) Experimental investigations on the respiratory function in diving mammals and birds. Hvalråd. Skr. 22, 1-131. 